\title{
Notes on the vocalizations of White-browed Hemispingus (Hemispingus auricularis)
}

\section{Peter Boesman}

In the following we briefly analyze and compare voice of White-browed Hemispingus (Hemispingus auricularis) with Black-capped Hemispingus (H. atropileus). We also try to quantify the extent of any vocal differences using the criteria proposed by Tobias et al. (2010), as a support for taxonomic review. We have made use of sound recordings available on-line from Xeno Canto (XC) and Macaulay Library (ML).

An overview of songs, illustrated with sonograms:

\section{H. atropileus}

Dawn song is a leisurely delivered long series of single whistles, some notes repeated several times, some uttered alternating, etc. Some notes are high-pitched, others cover a wide frequency range:

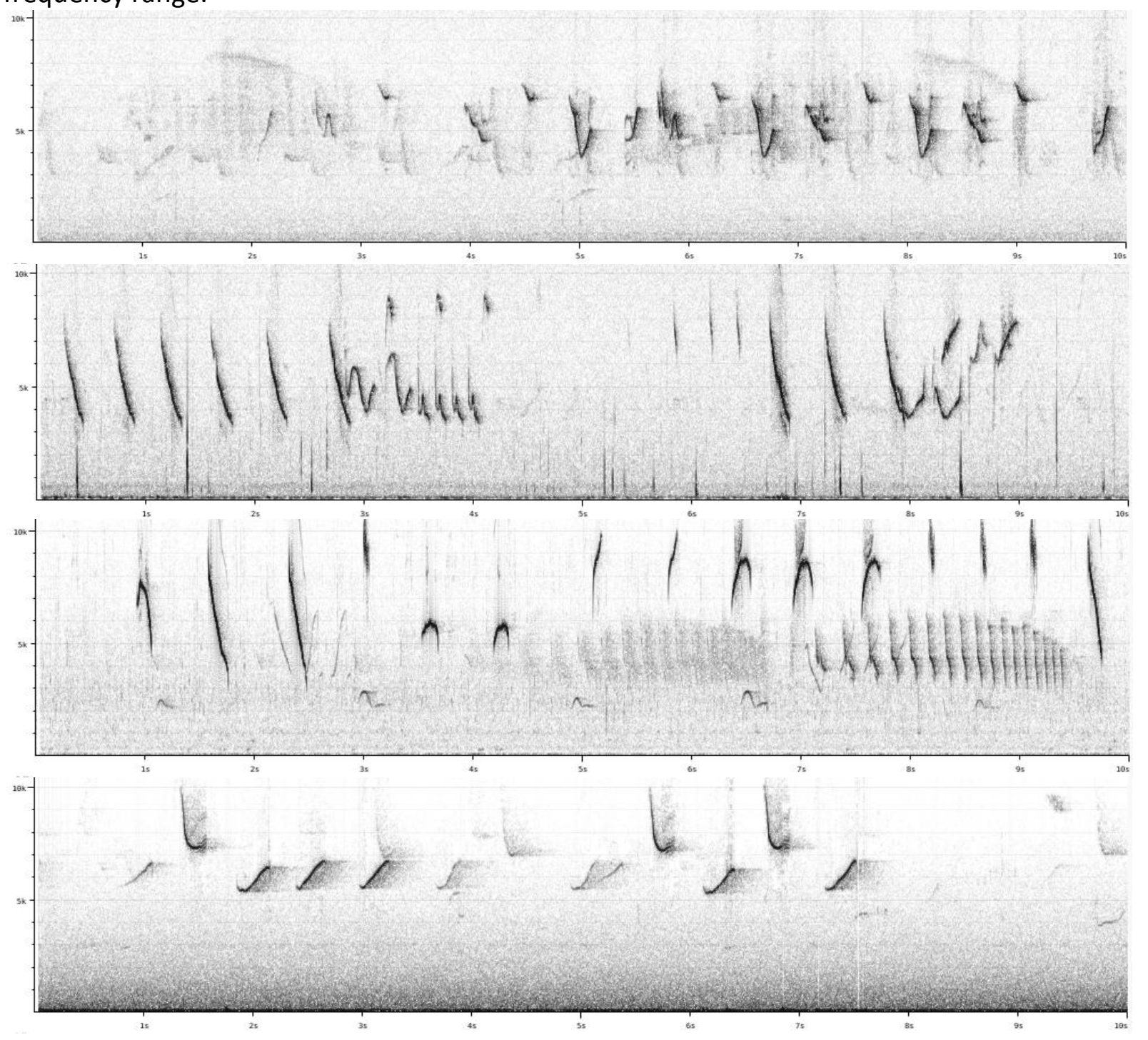




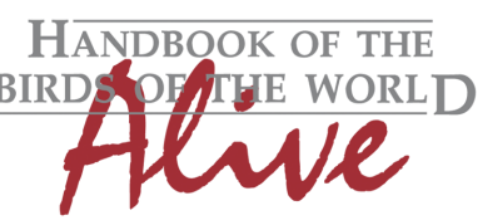

ORNITHOLOGICAL NOTES

Day-time 'song' or twitterings:

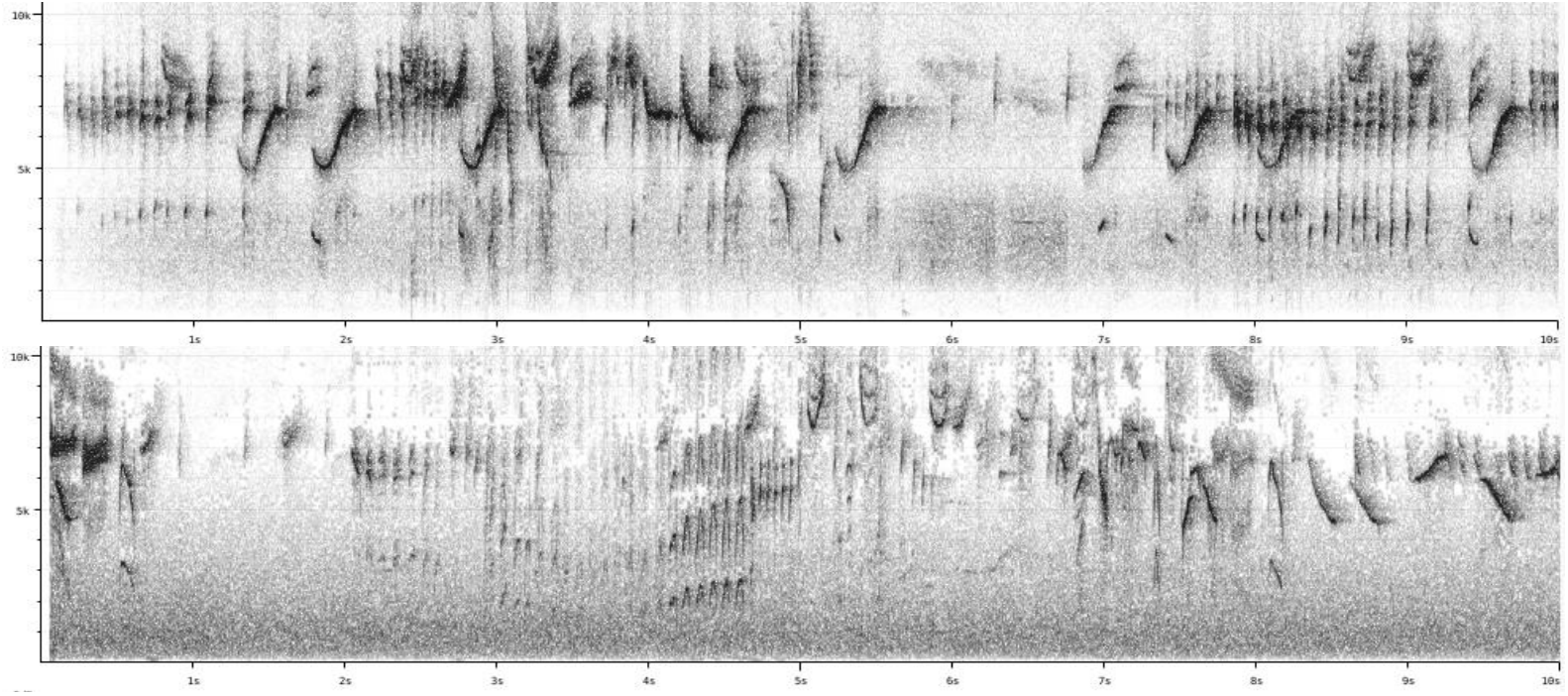

\section{H. auricularis}

Dawn song:
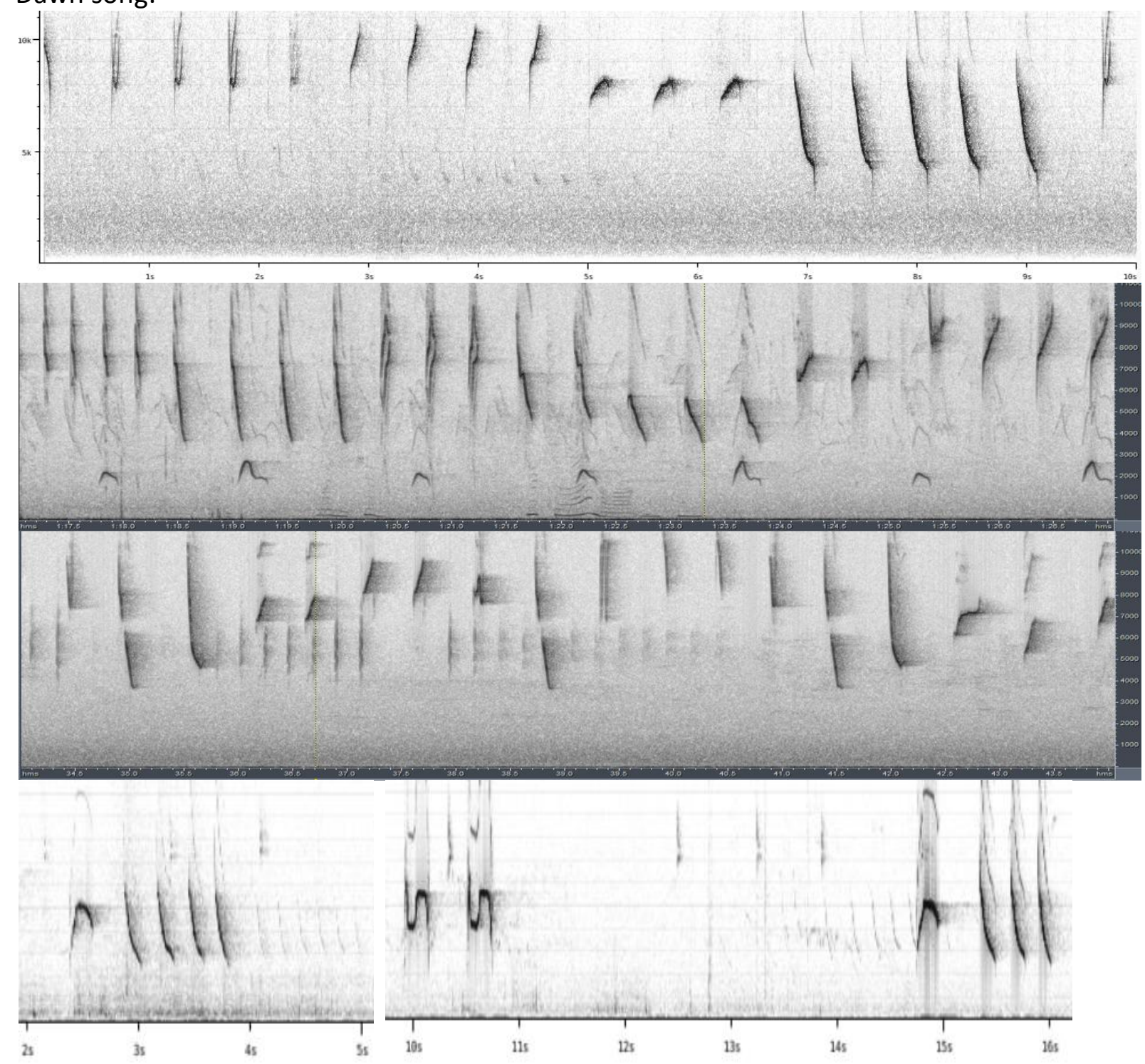

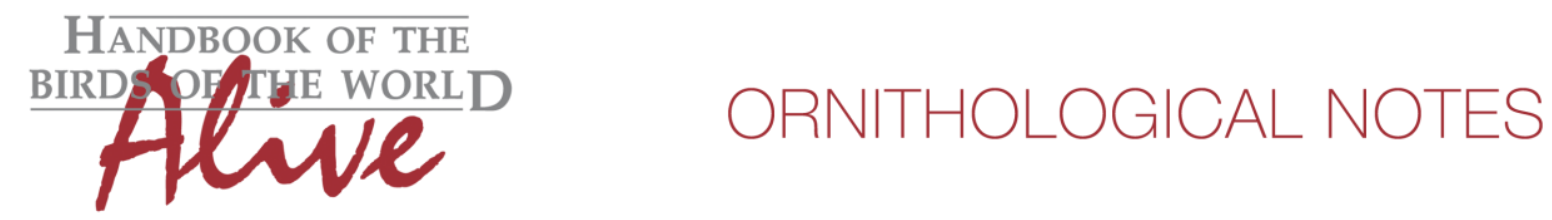

Day-time 'song' or twitterings:

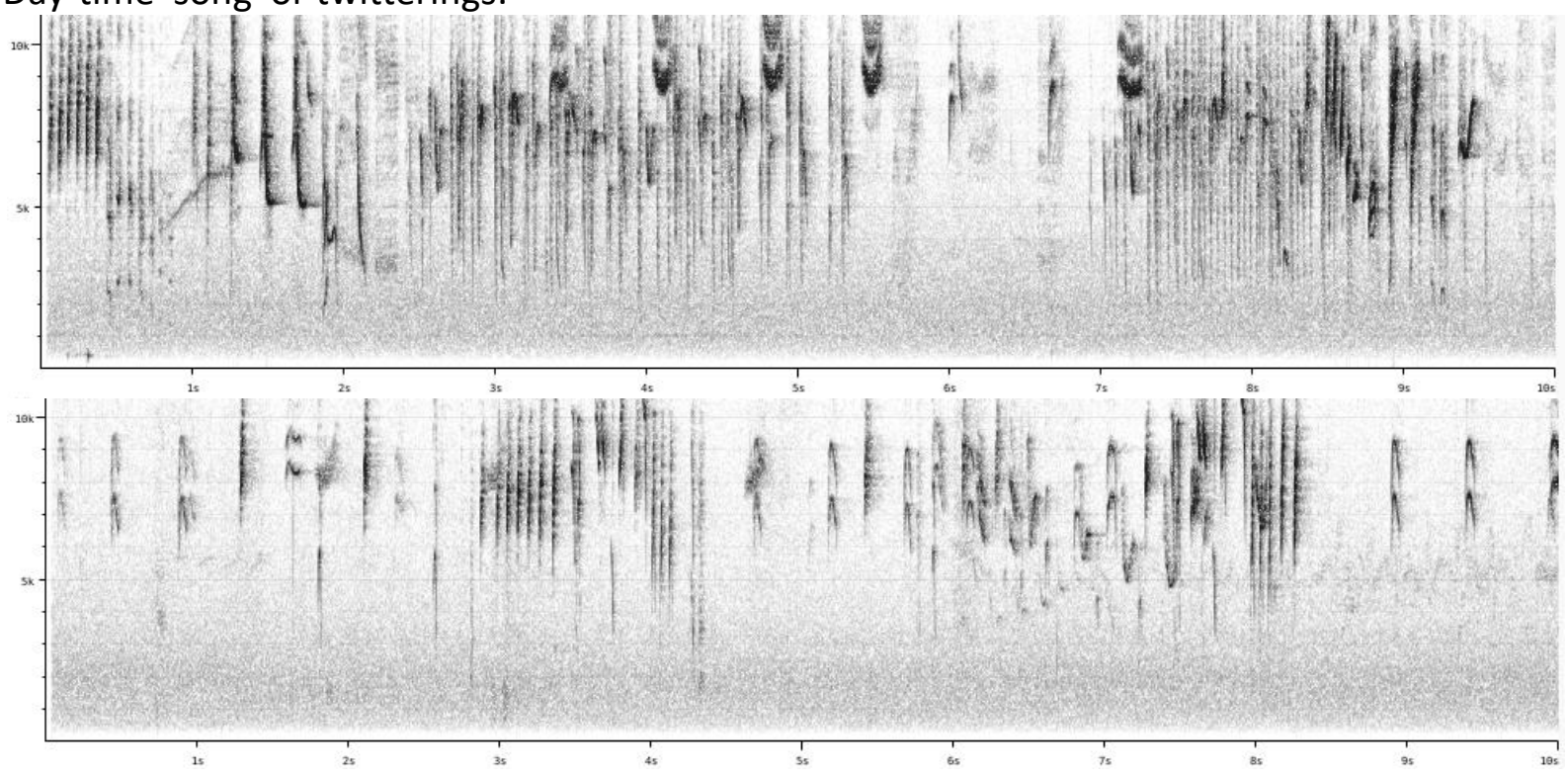

Dawn song of $H$. atropileus is apparently quite variable. Dawn song of $H$. auricularis seems to be somewhat more stereotypic, with many notes repeated 3-5 times and all recordings contain steeply downslurred notes covering a wide frequency range. Basic sound parameters are however very much the same (pace, note length, frequency range etc.).

A more in depth statistical analysis would be needed to detect any consistent differences, and at present probably not sufficient recordings are available to do so.

Daytime twitterings are also quite complex and would need a similar analysis to find any consistent differences.

All in all, vocal differences seem to be rather small ('minor'at most).

This note was finalized on 19th October 2016, using sound recordings available on-line at that moment. We would like to thank in particular the many sound recordists who placed their recordings for this species on XC.

\section{References}

Tobias, J.A., Seddon, N., Spottiswoode, C.N., Pilgrim, J.D., Fishpool, L.D.C. \& Collar, N.J. (2010). Quantitative criteria for species delimitation. Ibis 152(4): 724-746.

\section{Recommended citation}

Boesman, P. (2016). Notes on the vocalizations of White-browed Hemispingus (Hemispingus auricularis). HBW Alive Ornithological Note 442. In: Handbook of the Birds of the World Alive. Lynx Edicions, Barcelona. (retrieved from http://www.hbw.com/node/1287374 on 9 December 2016). 